\title{
The Residential Learning Community as a Platform for High- Impact Educational Practices Aimed at At-Risk Student Success
}

\author{
Bryan Hall ${ }^{1}$ and Tom O’Neal ${ }^{2}$
}

\begin{abstract}
This paper examines a pilot residential learning community (RLC) project at Indiana University Southeast. The RLC targeted first-generation students who were academically at-risk. The purpose of the project was to see whether the combination of several high-impact educational practices within the context of an $R L C$ would improve 1) student engagement, 2) academic performance, and 3) second-year retention/credit-hour completion.
\end{abstract}

Keywords: retention, persistence, at-risk students, first-generation students, learning communities, residential, student engagement, high-impact educational practices, assessment.

\section{Section One: Introduction}

During academic year 2013-2014, Indiana University Southeast (IU Southeast) ran a pilot residential learning community (RLC) that targeted first-year students highly at-risk of dropping out of college. The RLC's design was driven by the demonstrated efficacy of several high-impact educational practices (HIPs) identified by Kuh (2008), as well as by some intuitive assumptions about academic and social support. The RLC combined five HIPs: 1) learning communities, 2) first-year seminars (FYS), 3) writing intensive courses, 4) collaborative assignments, and 5) common (shared) intellectual experiences. In addition, the RLC incorporated supplemental instruction as well as required co-curricular and extra-curricular activities to create both academic and social support networks.

We took our definition of "at-risk" students from the IU Blueprint Committee for Student Attainment and the Indiana Commission for Higher Education (ICHE 2013-15). Whereas the former identifies first-generation college students as particularly at-risk, the latter views Pell-Grant eligibility as the most important at-risk characteristic. At IU Southeast, (Office of Institutional Effectiveness 2006) the on-time (four-year) persistence to graduation rate for undergraduates is $8.8 \%$, while the rate for first-generation, Pell-Grant eligible, southern Indiana students is just 2.6\%. Of all the regional sites of IU, this campus has the largest negative difference, along with IU Kokomo (Sorcinelli, 2012). The administration at IU Southeast has made clear that improving retention and on-time persistence is a top priority. There are also significant financial incentives for improving these figures.

The 2014 ICHE (2013-15) metric for performance funding contains financial incentives for 30 hour completion ( $\$ 750$ per student), 45 hour completion (\$1,210 per student), 60 hour completion (\$1,530 per student), at-risk (Pell-Grant eligible) degree completion (\$5,503 per student), overall degree completion (\$7,795 per student), and on-time (four-year) graduation (\$22,921 per student). Improvement in these areas is increasingly important since the percentage of state appropriations tied to performance funding is set to increase in future years (6\% in 2014,

\footnotetext{
${ }^{1}$ St. John’s University, 8000 Utopia Pkwy, Queens, NY 11439, hallb@stjohns.edu.

${ }^{2}$ Indiana University Southeast, 4201 Grant Line Rd., New Albany, IN 47150, joneal@ius.edu.
} 
$7 \%$ in 2015). For every at-risk student who graduates in four-years, IU Southeast receives a total of $\$ 39,709$ in ICHE performance funding. Furthermore, each student who persists to on-time graduation represents an additional $\$ 19,905.30$ in tuition and fees that the university would lose if the student were to drop out after the first year.

Although persistence is a pressing matter, it begins with retention which is why the ICHE formula incentivizes the latter as well. With this focus, the IU Southeast team designed a project that would use HIPs as a means to improve retention as well as student learning. We wanted to design a project, furthermore, that would have an immediate and tangible impact on our students. The first thing we did was complete an inventory analysis of all HIPs being implemented on our campus. We discovered through our study that learning communities were the only practice that had little campus history notwithstanding the fact that creating learning communities was an objective of the 2010-2015 IU Southeast Strategic Plan.

To provide some context for our review of the existing literature, as noted in Brownell and Swaner (2010), it is important to distinguish between residential learning communities (RLC), the model of our pilot project, and learning communities in general. A learning community can be as simple in nature as employing only block scheduling, with or without curricular collaboration, in which a cohort of students is registered for two or more courses together, or it can contain a variety of other features such as supplemental instruction, first-year seminar, common experience curricula, and extra-curricular and co-curricular activities. An RLC adds the element of on-campus living and can contain all or any combination of the aforementioned learning community components. Although we will examine some of the literature that discusses the learning community generally, our primary focus will be the literature that specifically investigates the effects of the RLC.

Sorcinelli (2012) notes that one of the main reasons that students at-risk of dropping out of college decide to leave is because they feel as if they do not belong in college. On affective surveys, $55.6 \%$ of first-year students at IU Southeast agreed or strongly agreed that they feel disconnected from the campus and its resources (IU Southeast Student Success Action Team 20122015). Such disincentives, together with a tendency to lack the academic skills needed for success, have contributed to first-generation students' lower retention and persistence to on-time graduation. $^{3}$

Studies have shown that the RLC model can be particularly effective at improving retention and persistence for at-risk student populations since the RLC focuses on integrating students with one another as well as the campus community. As Kuh (2008) notes, attending classes with cohort peers help members to establish relationships early. Engstrom and Tinto (2008) have observed that RLC programs aimed at at-risk students have been shown to improve their degree completion by as much as $10 \%$ when compared with their non-RLC peers. Kinzie, Gonyea, Shoup, and Kuh (2008) emphasize that first-generation students need to be specifically targeted since they are less likely than non-first-generation students to participate in learning communities. Brownell and Swaner (2010) have also provided an endorsement of learning communities as one among many HIPs that have a positive relationship to student GPA and retention. They also distinguish between the RLC and non-residential learning communities, noting that the former are more likely to foster faculty interaction, as well as peer-to-peer friendship and support, thereby enhancing greater engagement for students. Lindblad's (2000) concise summary of the Washington Center's

\footnotetext{
${ }^{3}$ For a study that discusses this problem both with regard to first-generation as well as low income (e.g., Pell Grant eligible) students, see Astin, A. \& Oseguera, L. (2005) Degree attainment rates at American colleges and universities revised edition, Los Angeles: Higher Education Research Institute. UCLA.
}

Journal of the Scholarship of Teaching and Learning, Vol. 16, No. 6, December 2016. josotl.indiana.edu 
study of 63 learning communities reached some other interesting conclusions: participants demonstrated a greater ability to synthesize and apply ideas, showed greater tolerance for and appreciation of differences, and had higher cumulative GPAs and persistence.

Self-reporting among students also supports the efficacy of learning communities. Kuh's (2008) as well as Zhao and Kuh’s (2004) research examines learning community features based on student responses to the National Survey of Student Engagement survey of student satisfaction, noting that HIPs integrated into learning communities particularly benefit "historically underserved students” (Kuh, 2008, p. 17). Tinto (2000) identified the positive effects learning communities and other HIPs have on student engagement, academic achievement, and retention. For example, FYS courses have a smaller class size which allows for greater student engagement and helps build cohort cohesion. As Sorcinelli's (2012) research has shown, FYS courses enhance success for first-year and traditionally underrepresented students. Kinzie and Gonya et al. affirm the potential to succeed with at-risk populations by using educational practices to validate students "in and out of the classroom" - by adopting "enabling, confirming, and supportive" processes to socialize them in the culture (p. 33). ${ }^{4}$

Combining HIPs has been shown to have a multiplier effect on student attainment (BrckaLorenz, 2012). Tinto and Goodsell-Love's (1993) study of three institutions' learning communities that employed linked courses, common experience curricula, and supplemental instruction each showed higher persistence rates and even higher cumulative GPA for participants in comparison to non-participants. When it comes to supplemental instruction specifically, Sorcinelli (2012) has reported that working with a supplemental instructor enhances student success for first-generation students. Finally, Andrade's (2007-08) extensive review of the learning community literature revealed that coordinated linked course offerings in conjunction with FYS were a common denominators for student attainment.

As mentioned above, learning communities can take on myriad forms, but the most basic construction consists of block scheduling. In this most basic form, there is no curricular coordination, but mere association provides an unstructured opportunity for students to establish rapport with each other. Stassen's (2003) survey of learning community programs found that even the relatively austere design of uncoordinated block scheduling still has modest effects on engagement and retention. Lichtenstein (2005), however, recommends a more integrated design for best results. Our project aimed to enhance the positive effects inherent to learning communities by adding a residential component, creating curricular/co-curricular bridges between the linked courses, and incorporating multiple HIPs into the RLC design.

Beyond the GPA as an academic performance measure, conspicuously absent from RLC literature, in both student affairs and individual disciplines, are direct measures of student learning outcomes. While the primary goal of Talburt and Boyles (2005) was to interrogate the core assumptions of how RLCs enculturate students, their work indirectly points out the dearth of evidence on the extent to which RLC students perform better academically than their non-RLC peers. Andrade's (2007-08) review of learning communities found only one program that performed a portfolio assessment of student writing compared to a control group. In addition to examining gains in average final grades, via a rubric-based direct assessment of student learning outcomes, our project sought to document specific, measurable gains in both disciplinary as well as basic college skills.

The overall purpose of our study was to discover whether combining multiple HIPs within

\footnotetext{
${ }^{4}$ See also, Redón (1994). Validating culturally diverse students: Toward a new model of learning and student development. Innovation in Higher Education. 19, 33-52.
}

Journal of the Scholarship of Teaching and Learning, Vol. 16, No. 6, December 2016. josotl.indiana.edu 
the context of an RLC would have a positive impact on student engagement and attainment. Our study had three hypotheses: 1) RLC students would become more engaged with their fellow students and the campus community than non-RLC students. 2) RLC students would perform better on academic skills assessments and have better final grades than non-RLC students in the same courses. 3) RLC students would be retained at a higher rate and complete more credit hours per year than non-RLC students from the same demographic (first-generation/Pell-Grant eligible).

The remainder of the paper is broken into three sections. The next section describes the design of the RLC as well as our methods for testing the above hypotheses. The penultimate section lays out the results of our pilot project in terms of the hypotheses. The final section makes recommendations intended to help others planning RLC projects for their own institutions.

\section{Section Two: Design and Methods}

Students lived together in a residence hall and enrolled in a set of three introductory general education courses linked through common content over the 2013-2014 academic year. Ethics provided the common content for the other courses and was offered as an FYS. The FYS component included units that helped the students acclimate to college. FYS courses also have a smaller class size which allows for greater student engagement and helps build cohort cohesion. In the fall, this course was linked with first-year Composition. In the spring, both courses were linked with Public Speaking. All of the courses had collaborative assignments. The three instructors worked together on every aspect of course design, including the common content, the skills they would emphasize, and the ways that skill mastery would be assessed. Special attention was paid to insure that critical thinking, written communication, and oral communication skills would be reinforced across the courses. Both the Ethics and Composition courses were writing intensive. The Ethics course also included a group debate project (itself a collaborative assignment) that helped prepare students for their speeches in the Public Speaking course. Likewise, both the Composition and the Public Speaking courses focused on generating and evaluating arguments both in written as well as oral form. One of the functions of the FYS component of the Ethics course was to introduce basic college skills (e.g., active reading and note taking) and the RLC was designed to reinforce these skills over the course of the academic year.

We used a popular Ethics primer, Rachels, The Elements of Moral Philosophy (2012) to provide common content across all three courses. In addition, both fall courses assigned Skloot, The Immortal Life of Henrietta Lacks (2011). The latter was IU Southeast's “common experience” book for that year. The university encourages all classes (and especially first-year courses) to adopt the common experience book and organizes a number of events around the book over the course of the academic year. The content from the Ethics course along with the common experience book provided the RLC students with a common (shared) intellectual experience, one that they could likewise share with the larger campus community through the common experience events.

Each course was assisted by a supplemental instructor, who worked closely with the faculty to design co-curricular and extra-curricular activities for the RLC students. Whereas the cocurricular activities reinforced the common content and skills introduced in the linked courses, the extra-curricular activities helped students to bond with one another while actively integrating the cohort into residential and campus life. Accompanied by the supplemental instructor and/or faculty, students were required to attend two events a month (one social, one intellectual). Finally, the supplemental instructor worked with the students twice a week on class work in special sessions outside of class. Essentially, the supplemental instructor acted as a dedicated tutor for the three courses 
while also reinforcing the basic college skills necessary for student success.

As mentioned above, the purpose of our project was to see whether the combination of several high-impact educational practices within the context of an RLC would improve 1) student engagement, 2) academic performance, and 3) second-year retention/credit-hour completion. For each of these three areas, we developed a hypothesis about the effectiveness of the RLC and tested these hypotheses over the course of the project. In order to test these hypotheses, we 1) created affective surveys to indirectly measure student engagement, 2) developed assessment tools to directly measure student learning, and 3) worked with the Office of Institutional Research (OIR) at our university to gather comparative data on retention/credit hour completion. Below we have listed our three central hypotheses as well as the various tests we developed to confirm/disconfirm each of them.

1. RLC students would become more engaged with their fellow students and the campus community than non-RLC students.

a. Test: RLC students report a higher level of campus engagement than students within the residence halls but not participating in the RLC.

b. Test: RLC students report a higher level of campus engagement than students not living on campus.

c. Test: RLC students report a high level of engagement with one another.

d. Test: RLC students report participating in more activities than their non-RLC peers.

2. RLC students would perform better on academic skills assessments and have better final grades than non-RLC students in the same courses.

a. Test: RLC students perform better on disciplinary skills assessments than students taking the same courses outside the RLC.

b. Test: RLC students perform better on active reading and note taking skills assessments than students taking the same courses outside the RLC.

c. Test: RLC students have higher final grades than students taking the same courses outside the RLC.

3. RLC students would be retained at a higher rate and complete more credit hours per year than non-RLC students from the same demographic (first-generation/Pell-Grant eligible).

a. Test: RLC students are retained to the second year at rates higher than non-RLC at-risk students.

b. Test: A higher percentage of RLC students complete 30 hours in their first year than other non-RLC at-risk students.

\section{Section Three: Results}

In order to test the first hypothesis above, we developed an online (Qualtrics) affective survey that was sent to the RLC students as well as other students taking similar classes. The survey asked about the student's class standing, whether the student lived on campus, and the number of campus activities the student participated in. There were also a number of affective questions. All students were asked to what degree they agreed with the statement that "I feel strongly connected to the campus community." The RLC students were additionally asked to what degree they agreed with the statement that "I feel connected to the members of my Residential Learning 
Community." The survey was administered broadly at the end of fall 2013 and again for RLC students at the end of spring 2014.

In the fall, there were 25 students who responded to the survey who lived off campus. Of these students, only $48 \%$ agreed or strongly agreed with feeling strongly connected to the campus community. There were 11 students who lived on campus but did not participate in the RLC that responded to the survey. Surprisingly, only $43 \%$ of these students agreed or strongly agreed with feeling strongly connected to the campus community. Since developing this feeling of connection is one of the primary purposes of residential life, we did not expect that these students would report a lower level of campus engagement than students who lived off campus. Of the 11 RLC students who responded to the survey (one had left college at this point), 73\% agreed or strongly agreed with feeling strongly connected to the campus community. Although we readily admit that the number of RLC students we were in a position to study was small, the survey still provides prima facie reason for believing that the first hypothesis passes the first two tests (1a and 1b) above. There is also reason to think that the hypothesis passes the third test (1c) since $82 \%$ agreed or strongly agreed with feeling connected to the other members of the RLC. When this survey was administered again at the end of spring 2014 to RLC students, both numbers rose. At the end of the academic year, $80 \%$ agreed or strongly agreed with feeling strongly connected to the campus community and $90 \%$ agreed or strongly agreed with feeling connected to the other members of the RLC. By this point, however, a second student had left college, which might itself have accounted for the increase.

The first hypothesis passes the final test (1d) as well. In fall 2013, RLC students, on average, participated in more campus activities than the other non-RLC residential students, and the latter participated, on average, in more campus activities than the students who lived off campus. Whereas none of the other students surveyed participated in more than nine events on campus, $27 \%$ of RLC students reported participating in more than nine events. Although RLC students were required to participate in at least six events (unlike non-RLC students), it stands to reason that these events had both a positive impact on the degree to which the RLC students felt engaged with the campus community as well as with one another relative to their non-RLC peers.

In semi-structured interviews at the end of the academic year, all of the students said that they thought the RLC was a positive experience. Living together in the dorms helped them to get as close as they did. This led them to open up with one another and feel comfortable calling one another out when someone missed class or an assignment. They also agreed that their favorite classes at IU Southeast were the ones that they took as part of the RLC. Students mentioned that the RLC helped in their transition from high school to college and that, in many ways, the RLC was like having your high school friends with you in college.

There were three tests for our second hypothesis above. First, students would master the skills associated with the individual disciplines that are linked. Second, students would improve their active reading and note taking skills. Third, students would have higher final grades. Passing the first test required that students within the RLC perform better on disciplinary skills assessments than students taking the same courses outside the RLC. The instructors teaching the linked courses in the fall semester (Ethics and Composition) collaborated on a rubric that could be used to assess student writing in Ethics courses (both in terms of content and structure). The rubric was used to assess student papers from the RLC Ethics course as well as two other sections of the same course though outside of the RLC. One of these sections was taught by the same instructor who taught the RLC course and was an FYS section. The other section was taught by a different instructor and was not an FYS section. The instructors of record assessed the papers using the same

Journal of the Scholarship of Teaching and Learning, Vol. 16, No. 6, December 2016. josotl.indiana.edu 
rubric though the instructor who taught the FYS sections assessed both rough and final drafts (scores separated by a slash below). ${ }^{5}$ Papers were assessed for each of the outcomes on a fourpoint scale: 4 = Excellent, $3=$ Sufficient, $2=$ In Need of Improvement, and $1=$ Poor. The below table presents the averaged results.

Table 1. Direct Assessment of Disciplinary Skills

\begin{tabular}{|c|c|c|c|}
\hline Learning Outcomes (Student will be able to) & RLC/FYS & $\begin{array}{l}\text { Non- } \\
\text { RLC/FYS }\end{array}$ & $\begin{array}{l}\text { Non-RLC/Non- } \\
\text { FYS }\end{array}$ \\
\hline $\begin{array}{l}\text { 1) state and explain each philosopher's view accurately } \\
\text { and concisely. }\end{array}$ & $2.5 / 3.2$ & $2.7 / 2.9$ & 2.7 \\
\hline $\begin{array}{l}\text { 2) make accurate and relevant distinctions between } \\
\text { different ethical positions. }\end{array}$ & $2.3 / 3.1$ & $2.8 / 3.1$ & 2.6 \\
\hline $\begin{array}{l}\text { 3) evaluate the relevance or effectiveness of a } \\
\text { particular ethical theory by comparing and contrasting it } \\
\text { with another. Relevant strengths and limitations of each }\end{array}$ & $2.7 / 3.0$ & $2.4 / 2.6$ & 2.6 \\
\hline $\begin{array}{l}\text { 4) anticipate the objections or counter-arguments that } \\
\text { engaged and informed readers may present. }\end{array}$ & $2.7 / 2.9$ & $2.2 / 2.3$ & 2.6 \\
\hline $\begin{array}{l}\text { 5) explain at least two ethical positions by applying } \\
\text { congruent analogies and/or relevant examples to a } \\
\text { particular moral issue. }\end{array}$ & $2.5 / 2.8$ & $2.7 / 2.9$ & 2.8 \\
\hline $\begin{array}{l}\text { 6) evaluate the relevance or effectiveness of an } \\
\text { ethical theory by comparing and contrasting it with } \\
\text { another as they both relate to a particular moral issue, } \\
\text { relevant strengths and limitations of each as they relate } \\
\text { to that moral issue are noted. }\end{array}$ & $2.4 / 2.7$ & $2.1 / 2.4$ & 2.3 \\
\hline $\begin{array}{l}\text { 7) anticipate the objections or counter-arguments that } \\
\text { engaged and informed readers may present with respect } \\
\text { to the moral issue in question. }\end{array}$ & $2.5 / 2.7$ & $2.0 / 2.3$ & 2.6 \\
\hline $\begin{array}{l}\text { 8) reject a particular position in favor of a different } \\
\text { position, providing ample and reasoned defense for } \\
\text { doing so. }\end{array}$ & $2.7 / 3.1$ & $2.1 / 2.3$ & 2.3 \\
\hline $\begin{array}{l}\text { 9) explain convincingly why the rejected particular } \\
\text { position referred to above cannot respond adequately to } \\
\text { the objections that face it. }\end{array}$ & $2.5 / 2.6$ & $2.2 / 2.3$ & 2.5 \\
\hline $\begin{array}{l}\text { 10) defend and reject various viewpoints, } \\
\text { representing them accurately. }\end{array}$ & $2.3 / 2.7$ & $2.1 / 2.3$ & 2.5 \\
\hline $\begin{array}{l}\text { 11) organize the paper sequentially and effectively } \\
\text { to facilitate reading. }\end{array}$ & $2.6 / 3.4$ & $2.0 / 2.7$ & 2.9 \\
\hline
\end{tabular}

$5 \quad$ Both the Ethics instructor as well as the Composition instructor assessed the final drafts of the papers for the RLC section of Ethics using the same rubric. Their respective scores have been averaged.

Journal of the Scholarship of Teaching and Learning, Vol. 16, No. 6, December 2016. josotl.indiana.edu 


\begin{tabular}{|l|l|l|l|}
\hline $\begin{array}{l}\text { 12) use a style appropriate to academic writing required } \\
\text { in introductory courses. }\end{array}$ & $2.6 / 3.5$ & $2.7 / 3.3$ & 2.9 \\
\hline $\begin{array}{l}\text { 13) attribute and document content appropriately and } \\
\text { thus avoids charges of plagiarism. }\end{array}$ & $2.9 / 3.6$ & $2.3 / 3.0$ & 3.8 \\
\hline 14) address the assignment prompt fully and concisely. & $3.4 / 3.4$ & $3.2 / 3.6$ & 3.3 \\
\hline
\end{tabular}

Comparing the sections taught by different instructors (i.e., RLC/FYS and non-RLC/nonFYS), using the RLC final drafts, the students in the RLC performed better than the students in the other course on twelve of the fourteen outcomes (86\%). The students were tied on one outcome (\#5) and the students in the non-RLC/non-FYS course performed better relative to only a single outcome (\#13). Even so, the non-RLC course did not include the additional FYS content (e.g., a unit dedicated to writing successfully in college) and students did not have the opportunity to improve their papers in light of comments they received on their rough drafts. Consequently, comparing these two courses does not really isolate the added academic value of the RLC itself.

This is why it is most useful to look at the two courses taught by the same instructor. In addition to both being FYS sections, they had the same course content, and the paper assignments were structured identically (prompts, rough/final drafts). Comparing these two courses, the most striking thing is how much better students in the RLC course performed not only on the rough draft (higher on ten of fourteen outcomes, or $71 \%$ of the outcomes), but also how their degree of improvement between the rough and the final draft was greater than students in the non-RLC iteration of the course. Although students in both sections showed the same degree of improvement on three of the fourteen outcomes, students in the RLC version of the course showed a greater degree of improvement on nine of the remaining eleven outcomes (82\% of the remaining outcomes). This is even true of one of the two outcomes where non-RLC students did marginally better than RLC students on the final draft (outcome \#5). Since the two courses were virtually identical considered in themselves, it seems plausible that the RLC component (living together, coordinated curricula, co-curricular activities, etc.) had a positive impact on student learning. The difference in student learning is even more striking, we believe, since the students in the RLC were the most at-risk students on campus (Pell-Grant eligible and first-generation) and were, on average, less academically prepared than their counterparts in the non-RLC version of the exact same course. Although both sets of students were assessed for fourteen separate learning outcomes, the non-RLC students showed greater improvement and a stronger final score on only one of these (outcome \#14). ${ }^{6}$ The preponderance of evidence suggests that the second hypothesis passes the first test (2a) above.

The next test for the second hypothesis is that RLC students perform better on active reading and note taking skills assessments than students taking the same courses outside the RLC. These are basic academic skills that FYS courses emphasize and that we reinforced through supplemental instruction in the RLC. For both active reading and note taking, the instructor of the FYS section of Ethics developed a rubric with specific learning outcomes for both active reading and note taking. The below table presents the results both for the RLC section of the FYS Ethics course as well as for the non-RLC section of the same course. Near the end of the semester, the instructor asked students to photocopy the reading they did for that day (with all of their marks

$6 \quad$ Although we no longer have copies of the marked-up papers, it is possible that the written comments on the RLC students' drafts did not emphasize underperformance relative to this outcome. That would explain why there was no change in relative performance between the rough and final drafts.

Journal of the Scholarship of Teaching and Learning, Vol. 16, No. 6, December 2016. josotl.indiana.edu 
and annotations). At the end of the class, the instructor asked students to turn in the lecture notes that they had taken for that day. After assessing both of these items, the instructor returned them to the students at the beginning of the following class. Again, student learning was assessed on a four-point scale: 4 = Excellent, 3 = Sufficient, $2=$ In Need of Improvement, and $1=$ Poor. The below table presents the averaged results.

Table 2. Direct Assessment of Basic Academic Skills

\begin{tabular}{|c|c|c|}
\hline Active Reading & RLC/FYS & Non-RLC/FYS \\
\hline 1) Student notes definitions of technical terms in margin. & 2.6 & 1.9 \\
\hline 2) Student writes summaries in their own words in margins of text. & 3.0 & 2.0 \\
\hline 3) Student numbers multiple ideas in an organized fashion. & 3.1 & 1.3 \\
\hline 4) Student notes when examples of a concept are used. & 2.9 & 1.6 \\
\hline $\begin{array}{l}\text { 5) Student writes down possible exam questions after reading a } \\
\text { section. }\end{array}$ & 1.4 & 1.2 \\
\hline 6) Student selectively underlines key words and phrases. & 3.1 & 3.7 \\
\hline \multicolumn{3}{|l|}{ Note Taking } \\
\hline $\begin{array}{l}\text { 1) Student's notes demonstrate that the student understood what } \\
\text { the instructor was talking about. }\end{array}$ & 3.6 & 3.6 \\
\hline $\begin{array}{l}\text { 2) Student's notes demonstrate that the student understood why } \\
\text { the instructor was talking about it. }\end{array}$ & 2.6 & 2.9 \\
\hline $\begin{array}{l}\text { 3) Student connects the notes to the readings and to material } \\
\text { covered earlier in the semester. }\end{array}$ & 2.0 & 1.8 \\
\hline 4) The student's notes are well organized. & 2.8 & 3.2 \\
\hline
\end{tabular}

Although there is not a dramatic difference in the quality of students' note taking, students in the RLC section of the course performed measurably better on most of the active reading outcomes than students in the non-RLC section of the course. We think differences can probably be attributed to the coordinated curriculum in the RLC, in particular repeated exposure to some of the same readings in both the Ethics and the Composition courses. Both of these courses emphasized active reading skills and these skills were reinforced during supplemental instruction. Even though the evidence is equivocal, there is some reason to believe that the second hypothesis passes this test (2b) at least with respect to active reading skills.

The final test of the second hypothesis is that RLC final grades would be higher than the final grades of students in the same courses outside the RLC. Since the FYS sections of Ethics were closest to one another in content and shared the same instructor, we have chosen to compare the RLC section of this course to the non-RLC section. Whereas the average final grade in the RLC section was a B (85.98\%) the average grade in the non-RLC section was a C- (72.03\%). Although the average final grade for the RLC section is quite a bit higher than the non-RLC section, two of the RLC students withdrew from the course while two of the non-RLC students failed for nonattendance (i.e., they should have withdrawn). If the latter's grades are factored out, then the average 
final grade for the non-RLC section becomes a $\mathrm{C}+$ (78.85). In either case, however, the second hypothesis passes its final test (2c) since the average final grade for the RLC section of Ethics is higher than the average final grade for the non-RLC section of the same course.

The final hypothesis is that there would be improved student retention to the second year and increased credit hour completion for RLC students in comparison to non-RLC students from the same demographic. We relied on IU Southeast's OIR for the data that would confirm or disconfirm this hypothesis. According to OIR, there was a 55\% second year retention rate for the fall 2013 - fall 2014 cohort of Pell-Grant eligible first-generation students at IU Southeast. The second year retention rate for students in the RLC was 58.3\% (7 out of 12). Prima facie it would seem that there is not a very big difference between the retention of RLC students and their nonRLC peers. The picture becomes more complicated, however, when the reasons why students left as well as where they went are considered.

Two of our students were lost in the first semester. The instructors learned that one of these students was extremely homesick and rarely stayed in the residence hall before dropping out of college. This student did not attend most of the RLC events and missed several classes. Arguably, the student did not even have the opportunity to benefit from the program before leaving the university. Although the second student lived in the dorms, participated in all the events, and attended class regularly, the student ultimately decided to go into the family business, one that did not require a college education. Of course, any student (whether in the RLC or outside of it) could decide to leave college for a similar reason.

Three other students decided to leave IU Southeast after successfully completing the first year. One student transferred to Harrison College for a program that IU Southeast did not offer. The second student transferred to Northern Kentucky University to play baseball for a NCAA program. The third transferred to Jefferson County Community College, but decided to come back to IU Southeast in spring 2015 and cited the campus community as one of her reasons for returning. If we include her in our retention figures, the number goes up to 67\%.

When you consider all of the first-year, Pell-Grant eligible, first-generation IU Southeast students who transferred to other institutions within the retention figures, the RLC appears even more successful. Using census data available from other universities, OIR determined that the overall percentage of first-year, Pell-Grant eligible, first-generation students who started at IU Southeast and continued into their second year (fall 2014) either at IU Southeast or another institution of higher learning was 59.5\%. Including the three transfer students in the RLC figures, however, raises the second year retention to $83.3 \%$ which is much higher than the norm for the same demographic. In any case, the third hypothesis passes the first test above (3a) since a higher percentage of RLC students were retained than non-RLC students from the same demographic. How much higher this percentage is, however, depends on how "retention" is defined (i.e. at the same institution vs. at any institution of higher learning).

Finally, ICHE defines on-time graduation as completing college in four years. In order to complete college in four years, students must average 30 credit hours per academic year (can include summer). At IU Southeast, only 25.9\% of Pell-Grant eligible first-generation students complete 30 credit hours in their first year. Five of the twelve RLC students (41.6\%), however, completed 30 credit hours in their first year. The third hypothesis passes the second test above (3b) since a higher percentage of RLC students completed 30 hours in their first year than non-RLC students from the same demographic. Although the academic and co-curricular structure of the RLC probably had something to do with this, it is also likely that the $\$ 1,500$ scholarship provided by Financial Aid played a role as well since this scholarship was renewable as long as the

Journal of the Scholarship of Teaching and Learning, Vol. 16, No. 6, December 2016. josotl.indiana.edu 
student completed 30 credit hours. This suggests, furthermore, that even small financial incentives can have a fairly dramatic impact on credit hour completion. Since $50 \%$ of the scholarship is covered by ICHE performance funding in case the student completes 30 hours (see section one), IU Southeast's investment was even less than originally budgeted. We will return to this theme again presently when discussing recommendations for sustainability in the final section.

\section{Section Four: Recommendations}

Even though the results of our study confirm the central hypotheses, suggesting that the RLC was effective at improving student engagement, academic performance, and retention/credit hour completion, there are nonetheless several things that we would have done differently in retrospect. This section makes several recommendations for those planning an RLC for their own institution. In addition to providing practical advice for RLC planners, we also suggest how their efforts could fruitfully add to the existing research on RLCs.

Money was by far the biggest hurdle, and it took a great deal of time to secure sufficient funds for the pilot project. With the help of administrators, however, we applied for and received funding for the project from the IU Blueprint Committee for Student Attainment $(\$ 15,600)$. This money was supplemented by Financial Aid offering housing stipends ( $\$ 1,500$ per student). The stipends were essential to making residential life a realistic option for students from this socioeconomic demographic. These stipends are also renewable as long as the students successfully complete 30 hours per academic year (putting them on schedule for on-time graduation). Unfortunately, the time it took to secure funding pushed back the timeline for the project in a way that made it difficult to recruit. By the time we had the money to launch a proper marketing campaign, many students within the demographic we were targeting had already made alternative plans or had schedules that precluded them from participating in the RLC. Others could not afford residence life (\$6,100 per year) even with the stipend. Finally, the window between when marketing started and when Residential Life needed commitments was only a few months which did not leave us much time. Although we had set aside 20 slots for the RLC, we were only able to recruit 12 students for the project. Consequently, although the results discussed in the previous section are highly suggestive, one must also bear in mind that the number of students studied was quite small.

To recruit an ample number of students, we recommend the planning and funding request process begin a year and a half before the RLC's proposed start date, enabling more time for coordination between the RLC planners, admissions, and advising personnel, those most involved with student outreach.

Two essential traits that we feel made this RLC experiment successful were the strong curricular and student progress collaboration between the three instructors of the linked sections. As mentioned above, the three instructors collaborated on the common content, agreed on the skills that would be emphasized, designed assignments that would mutually reinforce these skills, and created assessment tools that would measure students' mastery of these skills. In addition, ad hoc meetings discussing the progress of the cohort guided our approaches to helping each student with unique learning needs and adjustment issues.

Finally, although data abounds on the retention of individual groups of students at specific institutions through the first year, little data exists connecting persistence to graduation with 
participation in learning communities. ${ }^{7}$ Those planning RLC projects should work with their institutions to provide continuing support for and to track the progress of their cohorts at least through what is considered to be "on-time" graduation (typically the fourth through the sixth year) and publish these results. An even more pressing concern with the existing data, however, is that the numbers of students studied tend to be very small. Although cooperation between universities could yield larger study sizes, the differences in RLC design across universities calls into question the usefulness of combining retention/persistence data. The same concern faces any meta-analysis of existing studies. Consequently, those planning RLC projects should either 1) secure an on-going institutional commitment to repeat similarly structured RLCs on an annual basis, or 2) secure a one-time institutional commitment to fund several similarly structured RLCs that would run concurrently. ${ }^{8}$ Although we failed to secure the funding necessary to continue and/or scale up our project, those pursuing funding can use this study in conjunction with those discussed in section one to justify attempting to replicate our results over a longer time-line or on a larger scale.

In an environment in which higher education funding formulae increasingly reward retention and "on-time" graduation, there are strong incentives to act in ways that either limit educational access (e.g., increasing admissions standards) or that do not benefit our students academically (e.g., weakening degree requirements). Fortunately, programs like our RLC project that utilize HIPs help institutions to meet their financial goals without sacrificing educational access or academic quality. Our RLC targeted students who other institutions might not have admitted and provided them with the tools necessary to be successful in college. When trying to "sell” the RLC concept to an institution, planners should note the positive effect that RLCs have been shown to have on retention and insist that their projects be given the time necessary to demonstrate their financial sustainability (e.g., through performance funding) before the decision is made whether or not to discontinue institutional support.

In closing, it is important to recognize that no academic program, regardless of how well designed it might be, can guarantee that students will stay in school and have successful college careers. As long as students are guided by the same forces that guide the rest of us: shifting personal/career aspirations, financial problems, health issues, or family responsibilities, some may choose to leave or temporarily suspend their educations. Even so, the close personal bonds we developed with our students in the RLC opened a window into their motivations that would have likely stayed closed were it not for the program. Although we did lose some students, these students had established enough personal rapport with us to explain their reasons for leaving, reasons that often had to do with circumstances beyond the control of any academic program. Without the RLC, we (and by extension our institution) would have missed this opportunity to learn more about our students and the inherent limitations of what we are capable of doing as educators —an added value that only genuine mentoring can provide.

\section{Acknowledgements}

\footnotetext{
${ }^{7}$ Of the sources we reviewed, we found only one RLC study (Buch and Spaulding, 2008) that followed students through the seventh semester. Although it showed an $18 \%$ higher retention rate for RLC participants, it studied only twenty students.

${ }^{8}$ Stassen's (2003) analysis of retention only through the first year identifies the need for single institutions to create and maintain "a longitudinal student database" that would not only enable persistence to graduation tracking but would also contain profile information of entering RLC participants (p. 592).
}

Journal of the Scholarship of Teaching and Learning, Vol. 16, No. 6, December 2016. josotl.indiana.edu 
We would like to thank the IU Blueprint Committee for Student Attainment for the grant that funded this project and Associate Vice Chancellor Annette Wyandotte for help with the grant application. Thanks also to IU Southeast for additional support both financial and logistical. Finally, many thanks to Professor Jamie Kauffman who taught as an instructor in the RLC and supported this project from beginning to end.

\section{References}

Andrade, M.S. (2007-2008). Learning communities: Examining positive outcomes. Journal of College Student Retention, 9(1), 1-20.

Astin, A.W. \& Oseguera, L. (2005). Degree attainment rates at American colleges and universities. revised edition. Las Angeles: Higher Education Research Institute, UCLA.

BrckaLorenz, A. (2012, September) High-impact practices and student engagement. Paper presented at the Indiana University FACET Faculty Leadership Institute, Indianapolis: IN.

Brownell, J. \& Swaner, L. (2010). Five high-impact practices: Research on learning outcomes, completion, and quality. Washington D.C.: American Association of Colleges and Universities.

Buch, K. \& Spaulding, S. (2008). A longitudinal assessment of an initial cohort in a psychology learning community. Teaching of Psychology, 35, 189-193.

Engstrom, C.M \& Tinto V. (2008). Learning better together: The impact of learning communities on the persistence of low-income students. Opportunity Matters, 1, 5-21.

Indiana Commission for Higher Education Higher Education (2013-15). Performance funding formula model - Weighting and rates for pff. Indianapolis: IN.

IU Southeast Student Success Action Team 2012-2015. (2013). A summary report for the chancellor on task force actions for 2012-2013. New Albany: IN.

Kinzie, J. Gonyea, R. Shoup, R. \& Kuh, G.D. (2008). Promoting persistence and success of underrepresented students: Lessons for teaching and learning. New Directions for Teaching and Learning, 115, 21-38.

Kuh, G. D. (2008). High-impact educational practices: What they are, who has access to them, and why they matter. Washington D.C.: Association of American Colleges and Universities.

Lichtenstein, M. (2005). The importance of classroom environments in the assessment of learning community outcomes. Journal of College Student Development, 46(4), 341-356.

Lindblad, J. (spring 2000). Learning community assessment studies: What the Washington Center resources show. Washington Center News, 26, 27.

Journal of the Scholarship of Teaching and Learning, Vol. 16, No. 6, December 2016.

josotl.indiana.edu 
Office of Institutional Effectiveness at IU Southeast considers the 2006 cohort of full-time students (the most recent cohort for which data is available).

Rachels, R. (2012). The elements of moral philosophy. New York, NY: McGraw-Hill.

Redón, L. (1994). Validating culturally diverse students: Toward a new model of learning and student development. Innovation in Higher Education, 19, 33-52.

Skloot, R. (2011). The immortal life of Henrietta Lacks. New York, NY: Crown.

Sorcinelli, J. (2012). Blueprint for student attainment: The first-generation study. Bloomington: Indiana University.

Stassen, M. (2003). Student outcomes: The impact of varying living-learning community models. Research in Higher Education, 44(5), 581-613.

Talburt, S. \& Boyles, D. (2005). Reconsidering learning communities: Expanding the discourse by challenging the discourse. The Journal of General Education. 54(3), 209-36.

Tinto, V. (2000). What we have learned about the impact of learning communities on students? Assessment Update, 12(2), 1-2, 12.

Tinto, V. \& Goodsell-Love, A. (1993). Building community. Liberal Education, 79(4), 16-22.

Zhao, C. M. \& Kuh, G. D. (2004). Adding value: Learning communities and student engagement. Research in Higher Education, 45(2), 115-38. 